\title{
Time-pattern of adverse outcomes after an infection-triggered acute heart failure decompensation and the influence of early antibiotic administration and hospitalisation. Results of the PAPRICA-3 study
}

\author{
Òscar Miró ${ }^{1,2}$, Koji Takagi ${ }^{2,3,4^{*}}$, Etienne Gayat ${ }^{4,5}$, Víctor Gil ${ }^{1}$, Pere Llorens ${ }^{6}$, Francisco J. Martín-Sánchez ${ }^{7}$, \\ Javier Jacob ${ }^{8}$, Pablo Herrero-Puente ${ }^{9}$, Rosa Escoda ${ }^{1}$, María Pilar López-Díez ${ }^{10}$, Amparo Valero ${ }^{11}$, Marta \\ Fuentes $^{12}$, José M. Garrido ${ }^{13}$, Eva Salvo ${ }^{14}$, Miguel A. Rizzi ${ }^{15}$, Alfons Aguirre ${ }^{16}$, LisseteTravería Bécquer ${ }^{17}$, \\ Alberto Domínguez-Rodríguez ${ }^{18}$, Joan Padrosa ${ }^{1}$, Gemma Martínez ${ }^{1}$, Mattia Arrigo ${ }^{2,19}$, Yonathan Freund ${ }^{20}$, \\ Alexandre Mebazaa ${ }^{2,4,5}$
}

\footnotetext{
${ }^{1}$ Emergency Department, Hospital Clinic; Institut d'Investigació Biomèdica August Pi i Sunyer (IDIBAPS); University of Barcelona. Barcelona, Catalonia, Spain.

${ }^{2}$ GREAT Network.

${ }^{3}$ Cardiology and Intensive Care Unit, Nippon Medical School Musashi-Kosugi Hospital, Kawasaki, Japan. ${ }^{4}$ INSERM UMR-S 942, Paris, France.

${ }^{5}$ Department of Anaesthesiology and Critical Care Medicine, AP-HP, Saint Louis and Lariboisière University Hospitals; Universite Paris Diderot, Paris, France.

${ }^{6}$ Emergency Department, Short-Stay Unit and Home Hospitalization, Hospital General de Alicante, Spain

${ }^{7}$ Emergency Department, Hospital Clínico San Carlos, Universidad Complutense, Madrid, Spain

${ }^{8}$ Emergency Department, Hospital Universitari de Bellvitge, L'Hospitalet de Llobregat, Catalonia, Spain

${ }^{9}$ Emergency Department, Hospital Universitario Central de Asturias, Oviedo, Spain

${ }^{10}$ Emergency Department, Hospital Universitario de Burgos, Spain

${ }^{11}$ Emergency Department, Hospital Doctor Peset, Valencia, Spain

${ }^{12}$ Emergency Department, Hospital Universitario de Salamanca, Spain

${ }^{13}$ Emergency Department, Hospital Virgen de la Macarena, Seville, Spain

${ }^{14}$ Emergency Department, Hospital Universitario La Fe, Valencia, Spain

${ }^{15}$ Emergency Department, Hospital de la Santa CreuiSant Pau, Barcelona, Catalonia, Spain

${ }^{16}$ Emergency Department, Hospital del Mar, Barcelona, Catalonia, Spain

${ }^{17}$ Emergency Department, Hospital Universitario de Canarias, Tenerife, Spain

${ }^{18}$ Cardiology Department, Hospital Universitario de Canarias, Tenerife, Spain

${ }^{19}$ Department of Cardiology, University Heart Center, University Hospital Zurich, Switzerland.

${ }^{20}$ Emergency Department, Hopital Pitié-Salpêtrière, Assistance Publique-Hôpitaux de Paris, Sorbonne Université, Paris, France.
}

* Òscar Miró and Koji Takagi have equally contributed to this study and should both be considered as first author.

Address for correspondence: Òscar Miró, Emergency Department, Hospital Clínic, Villarroel 170, 08036 Barcelona, Catalonia, Spain

FAX number: 34.93.227.56.93

Phone number: 34.93.227.98.33 


\section{Email: omiro@clinic.cat}

Acknowledgments and funding: This study was partially supported by grants from the Instituto de Salud Carlos III supported with funds from the Spanish Ministry of Health and FEDER (PI15/01019, PI15/00773, PI18/00393, PI19/00456) and Fundació La Marató de TV3 (2015/2510). The "Emergencies: Processes and Pathologies" research group of the IDIBAPS receives financial support from the Catalonian Government for Consolidated Groups of Investigation (GRC 2009/1385 and 2014/0313). Xavier Rosselló has received support from the SEC-CNIC CARDIOJOVEN fellowship program. We thank Alícia Díaz for her professionalism in data management.

Conflict of interests: The authors state that they have no conflict of interests with the present work. The ICA-SEMES Research Group has received unrestricted support from Orion Pharma and Novartis. The present study has been designed, performed, analysed and written exclusively by the authors independently of these pharmaceutical companies.

Other investigators of the ICA-SEMES (Research group on Acute Heart Failure of the Spanish Society of Emergency Medicine):Cristina Gil (Hospital Universitario de Salamanca). Eva Salvo (Hospital La Fe de Valencia). Rosa Escoda, Sira Aguiló, Carolina Xipell, Carolina Sánchez, Josep M. Gaytan (Hospital Clínic de Barcelona). Antonio Noval (Hospital Insular de Las Palmas de Gran Canaria). José M. Torres (Hospital Reina Sofía de Córdoba). Amparo Valero (Hospital Dr. Peset de Valencia). Alfons Aguirre, María ÀngelsPedragosa (Hospital del Mar de Barcelona). Raquel Torres-Gárate (Hospital Severo Ochoa de Leganés, Madrid). María Isabel Alonso, Francisco Ruiz (Hospital de Valme de Sevilla). José Miguel Franco (Hospital Miguel Servet de Zaragoza). Susana Sánchez (Hospital Rio Ortega de Valladolid). Aitor Alquézar, Miguel Alberto Rizzi, Sergio Herrera (Hospital San Pau de Barcelona). Irene Cabello, Álex Roset (Hospital Universitari de Bellvitge, Barcelona). Héctor Alonso (Hospital Marqués de Valdecilla de Santander). Esther Rodríguez Adrada, Guillermo Llopis García (Hospital Clínico San Carlos, Madrid). José María Álvarez Pérez (Hospital Universitario de Burgos). Ana Belén Mecina (Hospital Universitario Fundación Alcorcón, Madrid). Joaquín Vázquez Álvarez, Marta Sánchez González, Belén Prieto, María García García (Hospital Universitario Central de Asturias). Víctor Marquina, Inmaculada Jiménez, Patricia Javaloyes, Néstor Hernández, BenjaminBrouzet, Ana López (Hospital General de Alicante). Juan Antonio Andueza (Hospital General Universitario Gregorio Marañón de Madrid), Rodolfo Romero (Hospital Getafe de Madrid). Roberto Calvache (Hospital de Henares de Madrid), María Teresa Lorca, Luis Calderón (Hospital del Tajo de Madrid) Beatriz Amores Arriaga, Beatriz Sierra (Hospital Clínico Lozano Blesa de Zaragoza), Pascual Piñera, José Andrés Sánchez Nicolás (Hospital General Universitario Reina Sofía de Murcia), Enrique Martín Mojarro (Hospital Sant Pau i Santa Tecla de Tarragona), LisetteTravería Bécquer (Hospital Universitario de Canarias de Tenerife), Lluís Llauger García, Gerard Corominas La Salle. (Hospital Universitari de Vic de Barcelona), Carmen Agüera Urbano (Hospital Costa del Sol de Marbella, Málaga), Ester Soy Ferrer (Hospital Josep Trueta de Girona). 


\section{ABSTRACT (300 words)}

Objective: To investigate whether patients with an acute heart failure (AHF) episode triggered by infection present different outcomes compared to patients with no trigger, with specific analysis of the time pattern for these hypothetical differences, and the effects of early antibiotic administration (EAA) and hospitalisation.

Methods: This is a secondary analysis of the EAHFE Registry, which includes consecutive AHF patients diagnosed in 41 emergency departments. We made two groups according to the AHF trigger: infection (G1) or none identified (G2). The primary outcome was 13-week (91-days) allcause mortality, and secondary outcomes were 13-week post-discharge mortality, readmission or combined endpoint. Comparisons are presented as unadjusted and adjusted (MEESSI risk score) hazard ratios (uHR/aHR) for G1 compared to G2 patients, also estimated by weeks. Stratified analysis by EAA (provided/not provided) and patient disposition (discharged/hospitalized) was performed.

Results: We included 6727 patients (G1=3973; G2=2754), aged $81(10)$ years, $54.3 \%$ females. The 13-week mortality uHR was $1.11(0.99-1.25 ; p=0.06$; with significant increases in the first 3 weeks), and the aHR was 0.91 (0.81-1.02; $\mathrm{p}=0.11)$. There were no differences in unadjusted secondary post-discharge outcomes (with only a significant increase in the risk of death in week 2); however, G1 outcomes significantly improved after adjustment: aHRs0.83 (0.71-0.96; $p=0.01$ ) for mortality (although an increased risk was present at week 2), $0.92(0.84-0.99 ; p=0.04)$ for readmission, and $0.92(0.85-0.99 ; p=0.04)$ for combined endpoint. We found a differentiated effect of hospitalisation ( $p<0.05$ for interaction; better post-discharge readmission and combined outcomes in $\mathrm{G} 1$ ); and a trend ( $p=0.06$ ) to lower mortality for $\mathrm{G} 1$ patients with EAA.

Conclusion: AHF triggered by infection is not associated with a higher mid-term mortality, and has better post-discharge outcomes; however, the first 3 weeks are an extremely vulnerable period. In this group of patients, hospitalisation limits the risk of adverse post-discharge events, and EAA probably reduces mortality. 


\section{INTRODUCTION}

Acute heart failure (AHF) is still associated with a high mortality, estimated at around $10 \%$ and $30 \%$ at one month and one year after decompensation, respectively ${ }^{1,2}$. Successive attempts to improve outcomes with the use of new drugs have faile ${ }^{3-5}$. In this scenario, efforts have been aimed at paying greater attention to the prehospital phase ${ }^{6-8}$ to better manage the comorbidities and patient frailty frequently associated with $\mathrm{AHF}^{9,10}$ in order to improve decision-making with respect to discharge after both emergency department care and hospitalisation ${ }^{11,12}$, and to provide more adequate post-discharge transitional plans to protect patients during the vulnerable phase $\mathrm{e}^{13,14}$. In this sense, the importance of recognizing and treating factors triggering a decompensation of AHF has been increasingly underlined. Based on a recent systematic review, triggers have been recognized in at least $50 \%$ of patients in all the previously published series, the most frequent being dietetic/therapeutic transgression, acute coronary syndrome, tachyarrhythmia and infection ${ }^{15}$. Very recently, Arrigo et al. reported that the each trigger can have a specific and different time pattern which can influence patient outcomes (conferring either protection or hazard) ${ }^{16}$. Accordingly, the current recommendations of the European Society of Cardiology (ESC) guidelines for the management of AHF advise early recognition and treatment of triggering factors, since they may have an impact on prognosis after an AHF decompensation ${ }^{17}$.

Taking this into account, infection is one of the triggers most frequently involved in AHF episodes, and leads the list of triggers in many series ${ }^{15}$. However, the relative frequency of infection is very heterogeneous, especially depending on the setting in which the patients were recruited. Indeed, the frequency can range from as high as the $58 \%$ observed in AHF patients hospitalised in internal medicine wards $^{18}$ to only the $6 \%$ reported in AHF patients hospitalised in a cardiology department ${ }^{19-20}$. There are also discrepancies in the influence of infection on mortality; while some authors have reported infection to have no impact ${ }^{21,22}$, others have described an increased risk of death, especially during hospitalisation and the first 2 to 4 weeks after decompensation, in comparison with patients with no identified trigger ${ }^{15,23}$. On the other hand, the relationship between infection and the risk of readmission has been poorly explored, and only one previous study has suggested that infection has no influence on the development of $\mathrm{AHF}^{22}$. Finally, the study setting of these studies was one of the main limitations against obtaining strong conclusions, since most only included AHF patients attended in a particular hospital ward by a particular medical team.

Bearing in mind all the above mentioned discrepancies and limitations, we aimed to evaluate the influence of infection as a trigger of an AHF episode on outcomes (not only limited to the risk of death) in consecutive patients diagnosed at emergency departments (ED). This setting was chosen in order to be as close as possible to the whole universe of patients with AHF. We were also especially interested in determining the time point at which the potential differences in risk occur. Finally, we investigated if early antibiotic administration (EAA) and patient disposition after ED care (discharge/admission) influence the outcomes of patients with an AHF episode triggered by infection. 


\section{MATERIAL AND METHODS}

\section{Setting}

The PAPRICA-3 (apocopate from the Spanish words PApel del los PRecipitantes de episodios de Insuficiencia Cardiaca Aguda; in English: Role of precipitants of AHF) study was designed as an exploratory, secondary analysis within the EAHFE Registry. The EAHFE Registry was initiated in 2007 and every 2-3 years carries out a 1-2-month recruitment period of all consecutive patients diagnosed with AHF in Spanish EDs participating in the project. To date, 5 recruitment phases (2007, 2009, 2011, 2014, and 2016) have been performed with the participation of $41 \mathrm{EDs}$ from community and university hospitals across Spain (representing about 13\% of the Spanish public health care system hospitals), enrolling a total of 13,791 AHF patients. The PAPRICA-3 study included data of the 11,360 patients recruited in phases 3 to 5 , since data on triggers of the AHF episode or data of readmission were not recorded in phases 1 and 2. Details of patient inclusion have been reported previously $y^{2,11}$. Briefly, patient enrolment is done by any attending emergency physician in the participating EDs, who receives specific study protocol instructions during a weekly ED meeting preceding patient recruitment. These physicians are responsible for the detection of potential cases of AHF. All suspected cases are confirmed by the principal investigator of each centre to ensure the patients meet the diagnostic criteria of AHF based on the Framingham clinical criteria ${ }^{24}$. If possible, the diagnosis is also confirmed by measurement of plasma natriuretic peptide and/or echocardiography during ED or hospital stay following the current ESC guideline recommendations ${ }^{17}$. The principal investigator of each centre is responsible for the final diagnostic adjudication of the cases. The only exclusion criterion for being included into the EAHFE Registry is a primary diagnosis of ST-elevation myocardial infarction (STEMI) while concurrently developing AHF (which occurs in about 3\% of AHF cases), as the majority of these patients bypass the ED and go directly to the catheterization laboratory. The EAHFE Registry does not include any planned intervention, and the management of patients is entirely based on the attending ED physician decisions. However, all of these physicians are aware of the ESC guidelines, which are the main reference for all emergency physician actions.

\section{Ethics}

The EAHFE Registry protocol was approved by a central Ethics Committee at the Hospital Universitario Central de Asturias (Oviedo, Spain) with the reference numbers 49/2010, 69/2011, $166 / 13$, and $160 / 15$. Due to the non-interventional design of the registry, Spanish legislation allows central Ethical Committee approval, accompanied by notification to the local Ethical Committees. All participating patients gave informed consent to be included in the registry and to be contacted for follow up. The PAPRICA-3 study was carried out in strict compliance with the Declaration of Helsinki principles.The authors designed the study, gathered, and analysed the data, vouched for the data and analysis, wrote the paper, and decided to publish.

\section{Design and variables recorded}

Patients with a final diagnosis of AHF in whom data regarding the presence of a trigger was recorded were considered for the analysis. The PAPRICA-3 study was designed to compare the outcomes of patients in whom an active infection was identified as being the precipitant factor of the AHF episode with the outcomes of patients in whom no precipitant was identified after 
extensive review of the clinical and complementary data of the episode. Adjudication of a trigger for the current episode of AHF was not performed centrally, but rather was proposed by the attending physicians and revised by the principal investigator of each centre, who was responsible for the final patient classificationIn the case of infection, the adjudication was done based on the presence of signs and symptoms of active infection, regardless of the site of infection, during 7 days prior to AHF diagnosis, in conjunction with a congruent temporal pattern with respect with the development of signs and symptoms of heart failure. The only exclusion criterion was the absence of follow-up for mortality, as this was the primary outcome evaluated in the present study (see below). Thirty-three independent variables were recorded, including demographic data (2 variables), comorbidities (10 variables), baseline status (3 variables), chronic treatments for heart failure ( 5 variables), vitals at ED arrival ( 3 variables) and analytical data in the ED (8 variables)(see Supplemental Table 1 for definitions). In order to adjust for the severity of AHF episode, we calculated the MEESSI risk score for every patient. This risk score has recently been reported to accurately estimate the risk of death during the following 30 days in patients diagnosed with $\mathrm{AHF}$ in the $\mathrm{ED}^{11,25}$.

\section{Outcomes}

The 13-week (91 days) all-cause mortality was the primary endpoint evaluated in the PAPRICA-3 study. As secondary endpoints, we recorded three main post-discharge outcomes, which were calculated for patients discharged alive from the hospital (in-hospital deaths were not included among these outcomes). They consisted in the 13-week post-discharge all-cause death, 13-week post-discharge readmission due to AHF, and 13-week post-discharge combined endpoint. Followup was performed through telephone contact and consultation of primary care and hospital medical records. Adjudication of events was made at an at-site level by the principal investigator of each centre participating in the study.

\section{Statistical analysis}

Continuous variables are expressed as mean and standard deviation (SD) or median and interquartile range (IQR) if not normally distributed, and discrete variables as absolute values and percentages. Comparison among groups was carried out using one-way ANOVA or the MannWhitney non-parametric test for continuous variables and the chi square test for discrete variables. Kaplan-Maier curves were plotted for both groups of patients and were compared by means of the log-rank test. The risk of having primary and secondary outcomes in patients with an AHF episode triggered by infection compared to those with no trigger was expressed by a hazard ratio (HR) calculated by Cox regression, first unadjusted and then adjusted for the MEESSI risk score. An analysis of interaction was made according to the stratification of patients based on EAA (considered to be present if a systemic antibiotic had been taken before ED consultation or was administered during ED stay) and disposition after ED care (hospitalisation or direct discharge home). We conducted exploratory analyses of the variation in relative HR of primary and secondary outcomes among those still alive in the cohort by time since admission. Following the same analytical strategy as Arrigo et al. $^{16}$, we used a maximally flexible approach to allow the HRs to vary over time. We divided the cohort into seven time periods, roughly balancing even numbers of events without being completely arbitrary: weekly for the first 4 weeks, then biweekly for the next 4 weeks, then combining the remaining weeks of the cohort, and 
estimating separate HRs for each time period. In addition, all these time point calculations were repeatedly adjusted for the MEESSI score. Since this was an exploratory analysis to interpret several different questions, no adjustment for multiple comparisons was made, because each question implies different numbers of comparisons, and therefore, standard confidence intervals (Cls) are reported and interpreted cautiously. In addition, due to the exploratory nature of our investigation, a pre-hoc sample size calculation was not made. Statistical significance was accepted if the $95 \% \mathrm{Cl}$ of the HRs excluded the value 1 , or the $p$ value was less than 0.05 . 


\section{RESULTS}

Of the 11,360 patients included in the EAHFE registry in phases 3 to 5 , in the present analysis we included 6,727patients for whom the primary outcome was recorded: 3973 corresponded to patients with an AHF episode triggered by an infection, and 2754 in which no trigger was identified (Figure 1). Overall, the patients were $81(10)$ years of age, $54.3 \%$ were female, and comorbidities were highly prevalent (the most frequent being hypertension, atrial fibrillation, diabetes mellitus, ischaemic cardiomyopathy, heart valve disease, chronic kidney disease, and chronic obstructive pulmonary disease). More than half of the patients had had previous episodes of AHF. The remaining patient characteristics are shown in Table 1 and, as can be seen, the two groups of patients differed in 16 out of the 33 characteristics. The median MEESSI risk score for the whole population was -2.8 points (IQR -3.6 to -2.0 ), and it was significantly higher ( $p<0.001$ by non-parametric Mann-Whitney test) in patients with infection (median -2.6, IQR -3.4 to -1.7 ) than in patients with no trigger (median -3.0, IQR -3.7 to -2.1), indicating that the former group had a higher risk of death during the AHF episode.

The overall 13 -week mortality was $11.0 \%$, and the unadjusted HR for patients with infection was 1.11 (0.99-1.25; $\mathrm{p}=0.06$ ) (Figure 2). On analysing the risk for individual time periods, we observed that this increase in mortality was restricted to the first three weeks (Figure 3). With respect to secondary endpoints, the 13-week post-discharge mortality, readmission and combined endpoint were $5.5 \%, 25.9 \%$ and $28.1 \%$ for the whole cohort, respectively, with an unadjusted HR for patients with infection of 0.97 (0.84-1.12; $p=0.69), 0.95$ (0.87-1.12; $p=0.26)$ and 0.97 (0.89-1.05; $\mathrm{p}=0.44$ ), respectively (Figure 2 ). Time-point analysis only detected a significant increase in mortality in patients with infection during week 2 after discharge (Figure 3 ).

After adjustment of outcomes for the severity of patient decompensation (estimated by the MEESSI risk score), there was no difference in the primary endpoint (aHR0.91; 0.81-1.02; $p=0.11$ ) (Figure 2), with no statistically significant difference at any time point (Figure 3). On the other hand, patients with infection as the trigger showed better secondary outcomes after adjustment; with 13-week post-discharge aHRs of $0.83(0.71-0.96 ; p=0.01)$ for mortality, 0.92 (0.84-0.99; $\mathrm{p}=0.04)$ for readmission, and $0.92(0.85-0.99 ; \mathrm{p}=0.04)$ for the combined endpoint (Figure 2). Nonetheless, the excess in post-discharge mortality risk in week 2 observed in unadjusted analyses still remained statistically significant after adjustment (Figure 3).

The stratified analysis showed a differentiated effect for patient disposition, with hospitalisation providing better post-discharge readmission ( $p$ for interaction 0.04 ) and combined endpoint ( $p$ for interaction 0.04 ) outcomes. On the other hand, EAA was systematically associated with better results for patients with infection compared to patients without a trigger in all the outcomes assessed, although this interaction did not achieve statistical significance for any outcome (Figure 4). 


\section{DISCUSSION}

The PAPRICA-3 study evaluated the effect of the presence of an infection triggering an episode of AHF in a large cohort of patients recruited at the ED. This fact minimises the bias of selecting only patients managed by a particular hospital department. The study focused not only on mid-term mortality, but also on all-cause mortality and the risk of readmission after discharge following an index AHF episode. In addition, this study performed a more in depth evaluation of the time pattern during which a potential increase in risk caused by infection happens; an aspect which has been poorly explored to date. Finally, the potential effect of EAA and hospitalisation, two factors that can modify outcomes, has also been investigated. The 3 main findings reported by the PAPRICA-3 study are discussed below.

The first conclusion of our work is that, although patients with an AHF decompensation triggered by an infection seem to have a higher risk of death during the following 13 weeks, this apparent increased risk of death disappears after adjustment for confounding factors. This indicates that probably the risk associated with the patients' characteristics and severity of the AHF episode is more important determinants of mortality than the infection itself. However, it is important to note that the first 3 weeks after ED decompensation are responsible for this apparent increase in mortality. Therefore, although AHF triggered by infection is not associated with an overall higher mid-term mortality, the first 3 weeks after the episode is a highly vulnerable period. This finding indicates the highest risk period during which clinicians should maintain a closer follow-up in order to improve patient outcomes. Indeed, even though there was no increase in mortality after adjustment, closer follow-up of patients during these first 3 weeks post-AHF might even lead to a better mid-term survival (13 weeks) in patients with infection-triggered AHF episodes compared to those with no identified trigger.

The second finding is that infection-triggered AHF decompensations have better post-discharge outcomes that AHF with no identified trigger. The presence of a cardiomyopathy non-related factor sensitive to correction likely makes it easier to apply a specific treatment (antibiotic) to these patients, which otherwise could not be done in AHF patients with unknown precipitants. Following reports of AHF patients being in a vulnerable phase following discharge ${ }^{13}$, researchers have been paying increasing attention to outcomes after patient discharge following the index event. Indeed, actions addressed to this period could provide enormous benefits. A very recent meta-analysis of 41 randomised trials testing transitional care interventions demonstrated that implementation of transitional plans at AHF patient discharge achieves a significant reduction of $8 \%$ and $29 \%$ in the risk of rehospitalisation and ED visits, respectively ${ }^{25}$. In addition, another recent meta-analysis described the benefits of heart failure clinics in reducing hospitalisation for AHF and all-cause mortality, which was greater among patients with recent ED visit or hospitalisation due to decompensation ${ }^{26}$. Again, time-point analysis of risks provides a key postdischarge outcome improvement, as it showed that during the second week after discharge there is a significant increase in mortality, which remains even after model adjustment. Although the PAPRICA-3 study was not designed to investigate the causes of this increment in death at this time point, we believe that close monitoring shortly after discharge is mandatory in these patients in order to improve the current patient outcomes. 
Finally, stratified analysis suggests that EAA and especially hospitalisation can have benefits in infection-triggered AHF decompensations. Although the administration of EAA did not show statistical significance, it was always associated with better HRs (and in the case of mortality this trend was close to statistical significance, with a $p$ for interaction of 0.06 ) than in patients not receiving antibiotics before or during ED care. In this latter group of patients, it is foreseeable (although we did not check this) that an antibiotic was provided during hospital admission or prescribed to take at home if the patient was discharged directly from the ED. Therefore, the absence of EAA does not necessarily equate with an absence of antibiotic treatment, and this fact has probably diluted the differences in outcomes found in the stratified analysis by EAA. Nonetheless, what seems to be more relevant and statistically significant is the relationship between hospitalisation and improved post-discharge outcomes in patients with an infectiontriggered AHF episode, especially the reduction of readmissions. Some authors have highlighted the increased risks for AHF patients entirely managed at the ED and discharged home without hospitalisation ${ }^{12,27-29}$, and the PAPRICA-3 findings highlight that this is true in AHF patients with infection. Although our results were obtained with a post-hoc subanalysis, we believe that direct discharge from the ED home in this subgroup of patients with AHF and concurrent infection should be made with extreme caution.

Our study has some limitations. First, this is a secondary analysis limited to hypothesis generation that requires confirmation in future trials. Second, since there was no sample size calculation due to the exploratory nature of the study, a type-II error cannot be excluded in some of the estimations made, especially in subgroup comparisons, in which fewer outcomes were taken into account - o - were included. Third, this a real life cohort, without intervention, and attending emergency physicians did not receive any specific instructions about patient management and disposition. Therefore, the exact indication for antibiotic administration is not known, and it was not possible to differentiate between bacterial and viral infections. Fourth, the diagnosis of AHF was based on clinical criteria, and in all the cases the final diagnosis of AHF was not supported by natriuretic peptide or echocardiographic criteria. The same occurs with respect to the definition of infection and its adjudication as a trigger of the AHF episode. Fifth, the patients were from a single country, and therefore, external validation of our results should be made by further studies in other countries. And sixth, data regarding site of infection, the kind of antibiotic used and duration of treatment, and how many patients deteriorated into septic shock were not recorded. Accordingly, we cannot infer the role of all these factors in our findings.

Despite all these limitations, we believe that the data obtained in the PAPRICA-3 study, which includes a large registry of consecutive cases of AHF diagnosed in the ED, strongly suggest that the co-existence of an infection is not, by itself, associated with a worse prognosis during an episode of AHF, and post-discharge outcomes could be even better than in patients with no trigger for the AHF episode. Additionally, the study pinpoints areas for outcome improvement, highlighting the need for closer follow-up during the first few weeks after the index episode and after patient discharge in order to reduce the risk of death, as well as hospitalisation in order to avoid post-discharge readmissions due to AHF. 


\section{REFERENCES}

1.- Chioncel O, Mebazaa A, Harjola VP, Coats AJ, Piepoli MF, Crespo-Leiro MG, et al. Clinical phenotypes and outcome of patients hospitalized for acute heart failure: the ESC Heart Failure Long-Term Registry. Eur J Heart Fail. 2017; 19:1242-1254

2.- Llorens $P$, Javaloyes $P$, Martín-Sánchez FJ, Jacob J, Herrero-Puente $P$, Gil V, et al. Time trends in characteristics, clinical course, and outcomes of 13,791 patients with acute heart failure. Clin Res Cardiol.2018; 107:897-913.

3.- O'Connor CM, Starling RC, Hernandez AF, Armstrong PW, Dickstein K, Hasselblad V, et al. Effect of nesiritide in patients with acute decompensated heart failure. N Engl J Med. 2011; 365:32-43.

4.- Packer M, O'Connor C, McMurray JJV, Wittes J, Abraham WT, Anker SD, et al. Effect of Ularitide on Cardiovascular Mortality in Acute Heart Failure. N Engl J Med. 2017; 376:19561964.

5.- European Society of Cardiology. Serelaxin fails to meet primary endpoints in phase 3 RELAXAHF-2 trial. Accessed: 30/09/2018. Available at: https://www.escardio.org/The-ESC/PressOffice/Press-releases/serelaxin-fails-to-meet-primary-endpoints-in-phase-3-relax-ahf-2-trial

6.- Miró O, Llorens P, Escalada X, Herrero P, Jacob J, Gil V, et al. Analysis of the different factors of prehospital care for patients with acute heart failure in Spain. The SEMICA study.Emergencias 2017; 29:223-230.

7.- Harjola P, Tolonen J, Boyd J, Mattila J, Koski R, Palomäki A, et al. The role of pre-hospital management in acute heart failure.Eur J Heart Fail. 2017;19:287-289.

8.-Harjola P, Harjola V-P. Can we do more for patients with acute heart failure before arrival at the hospital? Emergencias 2017:28-32.

9.- Formiga F, Moreno-Gonzalez R, Chivite D, Franco J, Montero A, Corbella X. High comorbidity, measured by the Charlson Comorbidity Index, associates with higher 1-year mortality risks in elderly patients experiencing a first acute heart failure hospitalization. Aging ClinExp Res. 2018; 30:927-933.

10.- Martín-Sánchez FJ, Christ M, Miró Ò, Peacock WF, McMurray JJ, Bueno H, et al. Practical approach on frail older patients attended for acute heart failure. Int J Cardiol. 2016; 222:6271

11.- Miró Ò, Rossello X, Gil V, Martín-Sánchez FJ, Llorens P, Herrero-Puente P, et al. Predicting 30day mortality for patients with acute heart failure in the emergency department: A cohort study. Ann Intern Med 2017; 167:698-705.

12.-Llorens P. Risk assessment in emergency department patients with acute heart failure: We need to reach beyond our clinical judgment. Emergencias.2018; 30:75-6.

13.-Greene SJ, Fonarow GC, Vaduganathan M, Khan SS, Butler J, Gheorghiade M. The vulnerable phase after hospitalization for heart failure.Nat Rev Cardiol.2015; 12:220-9. 
14.- Cowie MR, Anker SD, Cleland JGF, Felker GM, Filippatos G, Jaarsma T, et al. Improving care for patients with acute heart failure: before, during and after hospitalization.ESC Heart Fail. 2014;1:110-145.

15.-Aguirre Tejedo A, Miró O. Precipitating factors in acute heart failure: a review. Emergencias. 2017; 29:185-93.

16.- Arrigo M, Gayat E, Parenica J, Ishihara S, Zhang J, Choi DJ, et al. Precipitating factors and 90day outcome of acute heart failure: a report from the intercontinental GREAT registry. Eur J Heart Fail. 2017; 19:201-208.

17.- Ponikowski P, Voors AA, Anker SD, Bueno H, Cleland JG, Coats AJ, et al. 2016 ESC Guidelines for the diagnosis and treatment of acute and chronic heart failure: The Task Force for the diagnosis and treatment of acute and chronic heart failure of the European Society of Cardiology (ESC). Developed with the special contribution of the Heart Failure Association (HFA) of the ESC.Eur Heart J. 2016; 37:2129-200.

18.-Moraes P, Fonseca C, Marques F, Ceia F, Aleixo A. Acutely decompensated heart failure: characteristics of hospitalized patients and opportunities to improve their care. Rev Port Cardiol. 2006; 25:13-27.

19.- Pinho Gomes AC, Silva J, Azevedo LF, Almeida R, Pinho T, Maciel MJ. Characterization of acute heart failure hospitalizations in a Portuguese cardiology department. Rev Port Cardiol. 2013; 32:567-75.

20.- Liaqat A, Moshin N, Imtiaz A, Mahreen F, Nusrat N. Factors precipitating acute heart failure. Ann Paklnst Med Sci. 2014; 10:33-8.

21.- Hermida A, Pazo M, de la Fuente R, Lado FL, Hernández L, Rodríguez I; grupo SANTICOR. Epidemiological events related to decompensated heart failure. An Med Interna. 2008; 25 256-61.

22.- Miró O, Aguirre A, Herrero P, Jacob J, Martín-Sánchez FJ, Llorens P. PAPRICA-2 study: Role of precipitating factor of an acute heart failure episode on intermediate term prognosis. Med Clin (Barc).2015; 145:385-9.

23.- Fonarow GC, Abraham WT, Albert NM, Stough WG, Gheorghiade $M$, Greenberg BH, et al; for the OPTIMIZE-HF Investigators and Hospitals. Factors identified as precipitating hospital admissions for heart failure and clinical outcomes. Arch Intern Med. 2008; 168:847-54.

24.-Ho KKL, Anderson KM, Kannel WB, Grosssman W, Levy D. Survival after the onset of congestive heart failure in Framingham heart study subjects. Circulation 1993; 88:107-15.

25.-Vedel I, Khanassov V. Transitional care for patients with congestive heart failure: a systematic review and meta-analysis. Ann Fam Med. 2015; 13:562-71.

26.- Gandhi S, Mosleh W, Sharma UC, Demers C, Farkouh ME, Schwalm JD. Multidisciplinary heart failure clinics are associated with lower heart failure hospitalization and mortality: systematic review and meta-analysis. Can J Cardiol. 2017; 33:1237-1244.27. 
27.- Lee DS, Schull MJ, Alter DA, Austin PC, Laupacis A, Chong A, et al. Early deaths in patients with heart failure discharged from the emergency department: a population-based analysis. Circ Heart Fail. 2010; 3:228-235.

28.-Miró Ò, Gil V, Xipell C, Sánchez C, Aguiló S, Martín-Sánchez FJ, et al. IMPROV-ED study: outcomes after discharge for an episode of acute-decompensated heart failure and comparison between patients discharged from the emergency department and hospital wards. Clin Res Cardiol.2017; 106:369-378.

29.-Formiga F, Chivite D. Acute heart failure: Understanding the patient is essential. Emergencias.2018;30:145-6. 
Table 1: Characteristics of the patients included in the PAPRICA-3 study and comparison depending whether the acute heart failure episode was triggered by an infection or no trigger was identified.

\begin{tabular}{|c|c|c|c|c|c|}
\hline & $\begin{array}{c}\text { Total } \\
N=6,727 \\
n(\%)\end{array}$ & $\begin{array}{c}\text { Missing } \\
\text { values } \\
\mathrm{n}(\%)\end{array}$ & $\begin{array}{c}\text { Trigger: } \\
\text { INFECTION } \\
\text { N=3,973 } \\
n(\%)\end{array}$ & $\begin{array}{c}\text { Trigger: } \\
\text { NONE } \\
\text { IDENTIFIED } \\
\mathbf{N}=\mathbf{2 , 7 5 4} \\
\mathrm{n}(\%)\end{array}$ & p value \\
\hline \multicolumn{6}{|l|}{ Demographic data } \\
\hline Age (years) (mean (SD)) & $81.1(9.7)$ & $3(0.0)$ & $81.9(9.3)$ & $80.1(10.1)$ & $<0.001$ \\
\hline Female & $3,642(54.3)$ & $25(0.4)$ & $2,177(55.0)$ & $1,465(53.4)$ & 0.18 \\
\hline \multicolumn{6}{|l|}{ Comorbidities } \\
\hline Hypertension & $5,664(84.2)$ & $4(0.1)$ & $3,377(85.0)$ & $2,287(83.1)$ & 0.04 \\
\hline Diabetes mellitus & $2,788(41.5)$ & $6(0.1)$ & $1,636(41.2)$ & $1,152(41.9)$ & 0.57 \\
\hline Ischaemic heart disease & $1,972(29.3)$ & $4(0.1)$ & $1,139(28.7)$ & $833(30.3)$ & 0.16 \\
\hline Heart valve disease & $1,795(26.7)$ & $4(0.1)$ & $1,005(25.3)$ & $790(28.7)$ & 0.002 \\
\hline Atrial fibrillation & $3,363(50.0)$ & $3(0.0)$ & $2,012(50.6)$ & $1,351(49.1)$ & 0.22 \\
\hline Chronic kidney failure (creatinine $>2 \mathrm{mg} / \mathrm{mL}$ ) & $1,894(28.2)$ & $4(0.1)$ & $1,132(28.5)$ & $762(27.7)$ & 0.48 \\
\hline Cerebrovascular disease & $900(13.4)$ & $5(0.1)$ & $540(13.6)$ & $360(13.1)$ & 0.55 \\
\hline Peripheral arterial disease & $619(9.2)$ & $5(0.1)$ & $394(9.9)$ & $225(8.2)$ & 0.02 \\
\hline Chronic obstructive pulmonary disease & $1,809(26.9)$ & $5(0.1)$ & $1,242(31.3)$ & $567(20.6)$ & $<0.001$ \\
\hline Dementia & $962(14.3)$ & $5(0.1)$ & $667(16.8)$ & $295(10.7)$ & $<0.001$ \\
\hline Active neoplasia & $939(14.0)$ & $7(0.1)$ & $570(14.4)$ & $369(13.4)$ & 0.28 \\
\hline Prior episodes of acute heart failure & $4,061(60.8)$ & $47(0.7)$ & $2,414(61.2)$ & $1,647(60.2)$ & 0.42 \\
\hline \multicolumn{6}{|l|}{ Baseline status } \\
\hline Barthel Index (points) (mean (SD)) & $77(26)$ & $830(12.3)$ & $75(27)$ & $80(24)$ & $<0.001$ \\
\hline NYHA class III-IV & $1,655(26.2)$ & $418(6.2)$ & $1,006(26.7)$ & $649(26.5)$ & 0.35 \\
\hline Left ventricular ejection fraction (\%) (mean (SD)) & $51.5(15.3)$ & $3,003(44.6)$ & $52.4(14.9)$ & $50.4(15.7)$ & $<0.001$ \\
\hline \multicolumn{6}{|l|}{ Chronic treatments at home } \\
\hline Diuretics (any) & $5,137(78.6)$ & $193(2.9)$ & $3,008(78.0)$ & $2,129(79,5)$ & 0.16 \\
\hline ACE inhibitor or ARB & $3,676(56.3)$ & $193(2.9)$ & $2,151(55.8)$ & $1,525(56.9)$ & 0.35 \\
\hline Beta-blocker & $2,672(40.9)$ & $196(2.9)$ & $1,508(39.1)$ & $1,154(43.5)$ & $<0.001$ \\
\hline Mineralocorticoid-receptor antagonist & $1,136(17.4)$ & $193(2.9)$ & $618(16.0)$ & $518(19.3)$ & 0.001 \\
\hline Digoxin & $1,018(15.6)$ & $201(3.0)$ & $587(15.2)$ & $431(16.1)$ & 0.34 \\
\hline \multicolumn{6}{|l|}{ Vitals at ED during acute episode (mean (SD)) } \\
\hline SBP (mmHg) & $139(26)$ & $101(1.5)$ & $139(27)$ & $139(24)$ & 0.33 \\
\hline Heart rate (bpm) & $85(21)$ & $140(2.1)$ & $88(22)$ & $82(18)$ & $<0.001$ \\
\hline Room air oxygen saturation (\%) & $91.9(6.7)$ & $182(2.7)$ & $91.2(6.9)$ & $92.9(6.3)$ & $<0.001$ \\
\hline \multicolumn{6}{|l|}{ Results of blood tests at ED } \\
\hline Haemoglobin (g/L) (mean (SD)) & $121(20)$ & $59(0.9)$ & $120(20)$ & $121(19)$ & 0.02 \\
\hline Leukocytes (cells/ $\mu \mathrm{L}$ ) (median (IQR)) & $8.4(6.6-10.8)$ & $69(1.0)$ & $9.2(7.0-12.1)$ & $7.8(6.2-9.7)$ & $<0.001$ \\
\hline Glucose $(\mathrm{mg} / \mathrm{dL})($ mean $(\mathrm{SD}))$ & $149(89)$ & $123(123)$ & $155(101)$ & $140(62)$ & $<0.001$ \\
\hline Creatinine (mg/dL) (mean (SD)) & $1.34(0.80)$ & $80(1.2)$ & $1.35(0.78)$ & $1.34(0.82)$ & 0.60 \\
\hline Sodium (mmol/L) (mean (SD)) & $138.0(5.1)$ & $128(1.9)$ & $137.7(5.2)$ & $138.3(5.0)$ & $<0.001$ \\
\hline Potassium (mmol/L) (mean (SD)) & $4.42(0.69)$ & $423(6.3)$ & $4.42(0.70)$ & $4.41(0.68)$ & 0.61 \\
\hline Raised troponin (>99th percentile) & $1,954(55.9)$ & $3,230(48.0)$ & $1,128(55.8)$ & $826(56.0)$ & 0.87 \\
\hline NT-proBNP (pg/mL) (median (IQR)) & $\begin{array}{c}3,822 \\
(1,830-8,432)\end{array}$ & $3,611(53.7)$ & $\begin{array}{c}3,976 \\
(1,942-8,630)\end{array}$ & $\begin{array}{c}3,712 \\
(1,667-8,186)\end{array}$ & 0.04 \\
\hline
\end{tabular}

ACE: angiotensin-converting enzyme; ARB: angiotensin receptor blocker; ED: emergency department; AHF: acute heart failure. Bold p values denote statistical significance. NYHA: New York Heart Association; SBP: systolic blood pressure; SD: standard deviation; ED: emergency department; IQR: interquartile range 
Figure 1: Patient inclusion flow chart

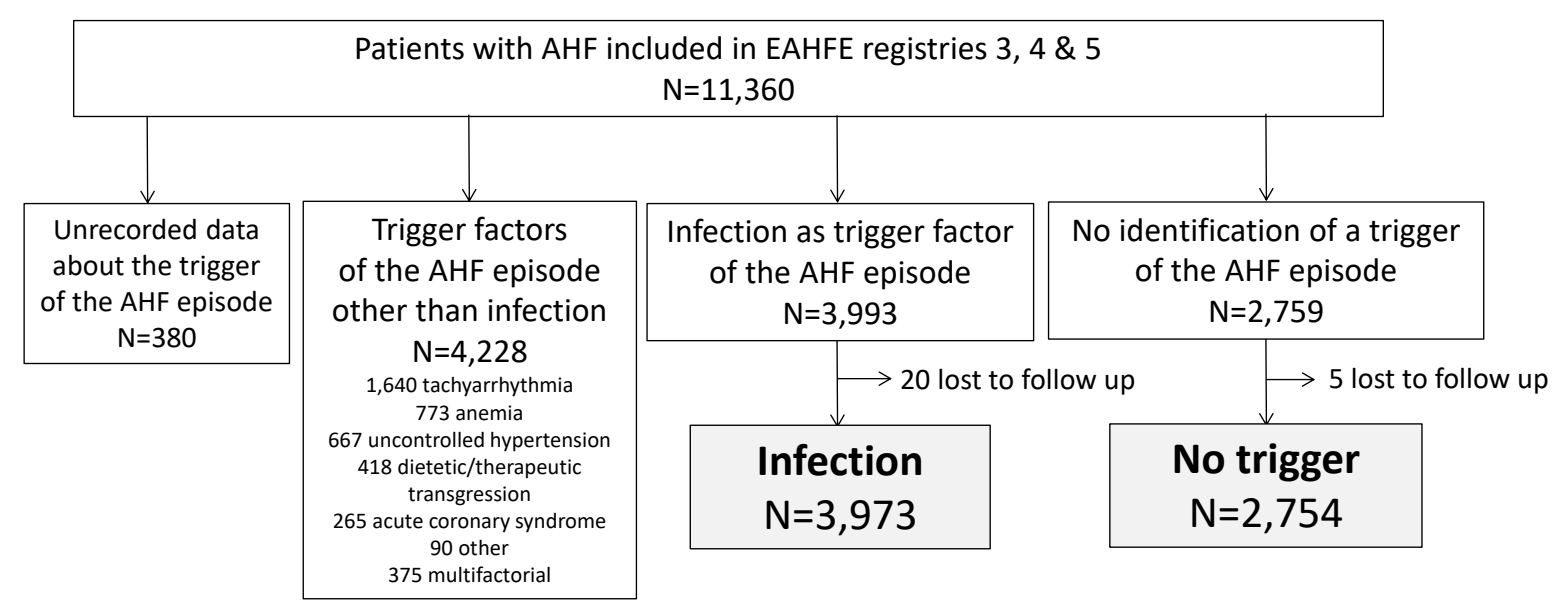

AHF: acute heart failure 
Figure 2: Kaplan-Meier curves of events for primary (upper panel) and secondary (middle panels) outcomes comparing patients with an acute heart failure episode triggered by an infection and those with no trigger identified, as well as results of unadjusted and adjusted hazard ratios for the first respect to the second group of patients (lower panel).

Primary outcome (all-cause mortality after index event)
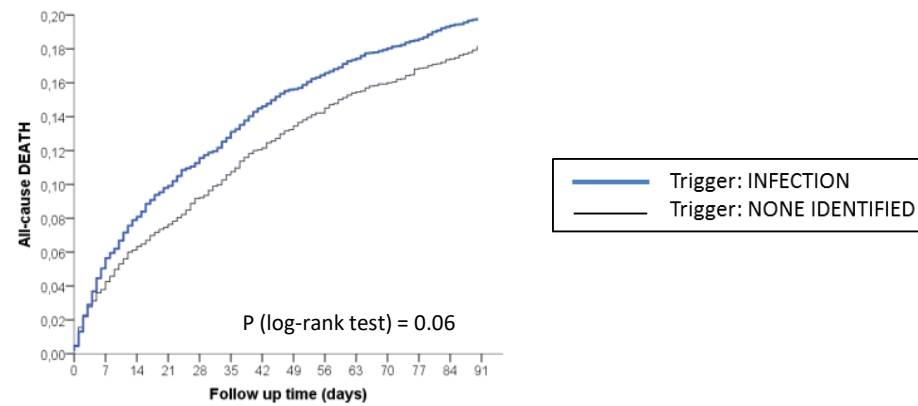

Secondary outcomes (after discharge from the index event)
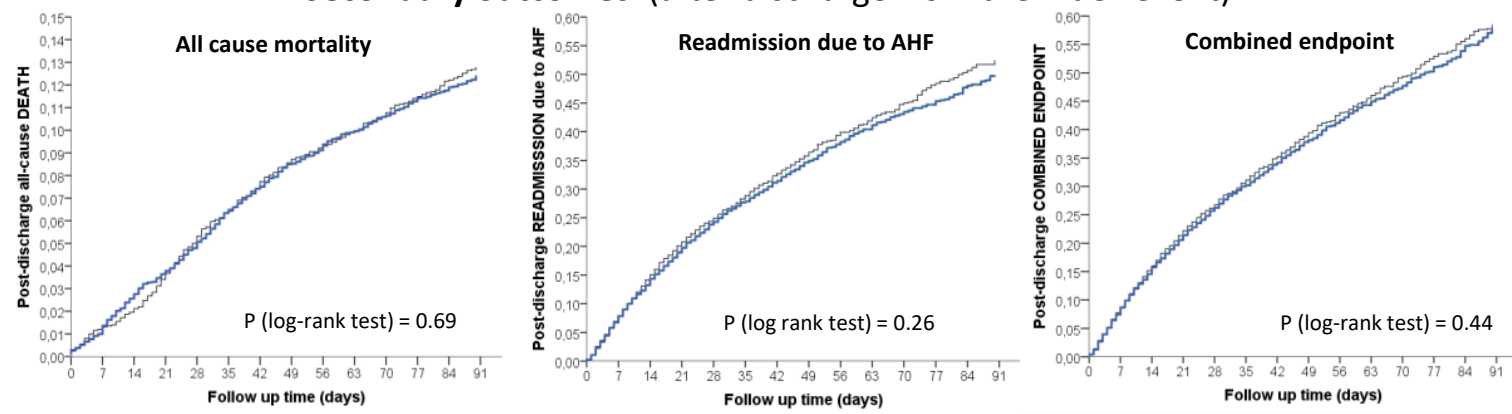

\begin{tabular}{|c|c|c|c|}
\hline & $\begin{array}{l}\text { \% patients with outcomes according to trigger } \\
\text { (infection vs none identified) }\end{array}$ & $\begin{array}{l}\text { Unadjusted HR for infection } \\
(95 \% \mathrm{Cl}) \\
\end{array}$ & $\begin{array}{l}\text { Adjusted HR for infection } \\
(95 \% \mathrm{Cl}) \\
\end{array}$ \\
\hline \multicolumn{4}{|l|}{ Primary outcome } \\
\hline 90-day all-cause mortality & $11.9 \%$ vs $9.6 \%$ & $1.11(0.99-1.25)$ & $0.91(0.81-1.02)$ \\
\hline \multicolumn{4}{|c|}{ Secondary outcomes (post-discharge) } \\
\hline 90-day all-cause mortality & $5.4 \%$ vs $5.7 \%$ & $0.97(0.84-1.12)$ & $0.83(0.71-0.86)$ \\
\hline 90-day readmission due to AHF & $25.6 \%$ vs $26.3 \%$ & $0.95(0.87-1.04)$ & $0.92(0.84-0.99)$ \\
\hline 90-day combined endpoint & $27.8 \%$ vs $28.6 \%$ & $0.97(0.89-1.05)$ & $0.92(0.85-0.99)$ \\
\hline
\end{tabular}

Bold numbers in table denote statistical significance. 
Figure 3: Time trend of hazard ratios for patients with an acute heart failure episode triggered by infection compared to patients with no trigger identified along the different time periods for primary and secondary outcomes.

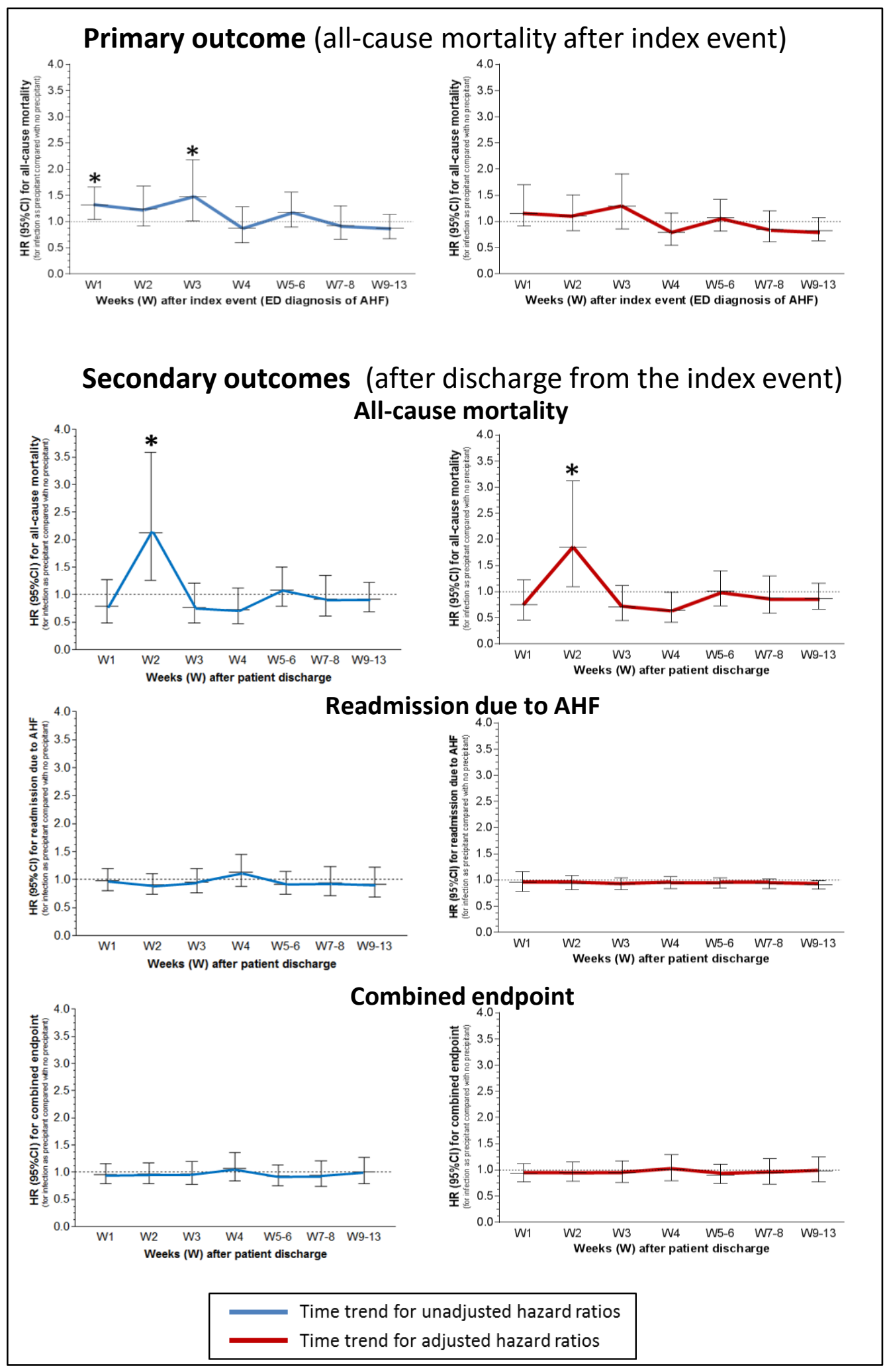

Asterisks denote $p<0.05$ for patients with infection compared to patients with no trigger. 
Figure 4: Adjusted analysis of primary and secondary outcomes stratified by early antibiotic therapy and final disposition after emergency department care.

\begin{tabular}{|c|c|c|c|c|c|c|c|}
\hline & $\begin{array}{r}\text { Hazard rat } \\
\text { For patients treated with AH } \\
\text { (respect to patients with } A H\end{array}$ & $\begin{array}{l}\text { tio }(95 \% \mathrm{Cl}) \\
\mathrm{HF} \text { triggered by an infection } \\
\text { IF with any trigger identified) }\end{array}$ & & $\begin{array}{l}95 \% \\
\text { lower }\end{array}$ & $\begin{array}{c}95 \% \\
\text { upper }\end{array}$ & $\begin{array}{c}P \\
\text { value }\end{array}$ & $\begin{array}{c}P \\
\text { value }\end{array}$ \\
\hline & 0.0 & $.0 \quad 2.0$ & $\mathrm{HR}$ & limit & limit & (HR) & (int.) \\
\hline $\begin{array}{l}\text { 13-WEEK ALL-CAUSE MORTALITY (primary end point) } \\
\text { Early antibiotic therapy? }\end{array}$ & & & & & & & \\
\hline $\begin{array}{r}\text { Early antibiotic therapy? } \\
\text { Not }\end{array}$ & & & 0.91 & 0.78 & 1.05 & 0.20 & 0.06 \\
\hline 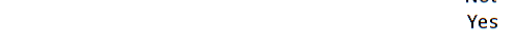 & $\longrightarrow$ & & 0.68 & 0.51 & 0.92 & 0.01 & \\
\hline Hospitalization after ED care? & & & & & & & 0.99 \\
\hline Not & & 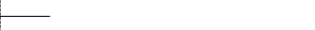 & 0.85 & 0.62 & 1.17 & 0.32 & \\
\hline Yes & & & 0.87 & 0.76 & 0.99 & 0.03 & \\
\hline 13-WEEK POST-DISCHARGE ALL-CAUSE MORTALITY & & & & & & & \\
\hline Early antibiotic therapy? & & & & & & & 0.36 \\
\hline Not & & & 0.84 & 0.70 & 1.02 & 0.07 & \\
\hline Yes & - & 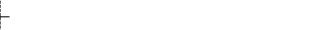 & 0.68 & 0.45 & 1.03 & 0.07 & \\
\hline Hospitalization after ED care? & & & & & & & 0.59 \\
\hline Not & & - & 0.74 & 0.52 & 1.06 & 0.10 & \\
\hline Yes & - & & 0.82 & 0.69 & 0.97 & 0.02 & \\
\hline 13-WEEK POST-DISCHARGE READMISSION DUE TO AHF & & & & & & & \\
\hline Early antibiotic therapy? & & & & & & & 0.15 \\
\hline Not & $\rightarrow$ & & 0.91 & 0.81 & 1.01 & 0.08 & \\
\hline Yes & $\because$ & & 0.75 & 0.58 & 0.96 & 0.02 & \\
\hline Hospitalization after ED care? & & & & & & & 0,04 \\
\hline Not & & 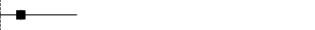 & 1.07 & 0.91 & 1.26 & 0.43 & \\
\hline Yes & $\longrightarrow$ & & 0.82 & 0.79 & 0.97 & 0.01 & \\
\hline 13-WEEK POST-DISCHARGE COMBINED ENDPOINT & & & & & & & \\
\hline Early antibiotic therapy? & & & & & & & 0.13 \\
\hline Not & $\because-1$ & & 0.90 & 0.81 & 1.00 & 0.06 & \\
\hline Yes & $\longrightarrow$ & & 0.75 & 0.59 & 0.94 & 0.02 & \\
\hline Hospitalization after ED care? & & & & & & & 0.04 \\
\hline Not & $\longrightarrow$ & 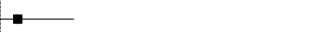 & 1.06 & 0.90 & 1.25 & 0.48 & \\
\hline Yes & $\rightarrow-$ & & 0.88 & 0.80 & 0.97 & 0.009 & \\
\hline
\end{tabular}

Bold $p$ values denote statistical significance. 
Supplemental Table 1: Dictionary of the variables included in the present study.

\begin{tabular}{|c|c|}
\hline \multicolumn{2}{|l|}{ DEMOGRAPHICS } \\
\hline Age & $\begin{array}{l}\text { Age calculated as the difference in decimal years between the date of inclusion in the study } \\
\text { and the date of birth. }\end{array}$ \\
\hline Sex & Male/Female \\
\hline \multicolumn{2}{|l|}{ MEDICAL HISTORY } \\
\hline Hypertension & $\begin{array}{l}\text { Indicate if the patient has arterial hypertension because this is shown under previoius clinical } \\
\text { history or the patient is receiving specific treatment. }\end{array}$ \\
\hline Diabetes Mellitus & $\begin{array}{l}\text { Indicate if the patient has diabetes mellitus because this is shown under previous clinical } \\
\text { history or the patient is receiving specific treatment. }\end{array}$ \\
\hline Ischaemic heart disease & $\begin{array}{l}\text { Indicate if the patient has any form of ischaemic heart disease (SCASEST, SCACEST, unstable } \\
\text { angina, stable angina, } \mathrm{ACl} \text {, etc) because this is shown under previous clinical history or the } \\
\text { patient is receiving specific treatment. }\end{array}$ \\
\hline Heart valve disease & $\begin{array}{l}\text { Indicate if the patient has any type of clnically significant heart valve disease according to an } \\
\text { ultrasound or haemodynamic study reported in the previous clinical history. }\end{array}$ \\
\hline Atrial fibrillation & $\begin{array}{l}\text { Indicate if the previous history describes permanent or chronic atrial fibrillation or an ECG } \\
\text { performed within the previous year shows atrial fibrillation and this continues to be present. }\end{array}$ \\
\hline Chronic kidney disease & $\begin{array}{l}\text { Indicate if the patient has chronic renal insufficiency or chronic kidney disease or if analyses } \\
\text { over the previous year show creatininevalues }>2 \mathrm{mg} / \mathrm{dL} \text {. }\end{array}$ \\
\hline Cerebrovascular disease & $\begin{array}{l}\text { Indicate if the patient has had a previous cerebrovascular accident or cerebrovascular disease } \\
\text { because this is described in the clinical history or shown in CT or MR imaging studies within } \\
\text { the previous year and reported as cerebrovascular disease. }\end{array}$ \\
\hline Peripheral artery disease & $\begin{array}{l}\text { Indicate if the patient has peripheral artery disease in either the lower extremities or carotid } \\
\text { artery, and if the patient is receiving specific treatment, has undergone specific surgery (by- } \\
\text { pass of lower extremities, endarterectomy, etc.) or there is previous history of an ankle } \\
\text { brachial index }<0.90 \text {. }\end{array}$ \\
\hline Dementia & Indicate if the patient has a previous clinical diagnosis of dementia performed by a doctor. \\
\hline Active neoplasia & Indicate if the patients has an active neoplasm \\
\hline Prior episode of heart failure & $\begin{array}{l}\text { Indicate if the patient has heart failure, is receiving specific treatment or the clinical history } \\
\text { reports previous episodes of AHF. }\end{array}$ \\
\hline \multicolumn{2}{|l|}{ BASELINE STATUS } \\
\hline Baseline Barthel index & Barthel index value of the patient at least 15 days prior to the date seen in the ED. \\
\hline $\begin{array}{l}\text { Baseline functional grade for dyspnoea } \\
\text { according to the NYHA scale }\end{array}$ & $\begin{array}{l}\text { Indicate the functional grade of basal dyspnoea (in the } 15 \text { days prior to the exacerbation } \\
\text { episode) of the patient according to the NYHA scale. }\end{array}$ \\
\hline Left ventricular ejection fraction & $\begin{array}{l}\text { Indicate left ventricular ejection fraction determined by echocardiography during admission of } \\
\text { current episode or, if not determined, the last one determined during the six previous months }\end{array}$ \\
\hline \multicolumn{2}{|l|}{ CHRONIC TREATMENT AT HOME } \\
\hline Diuretics & $\begin{array}{l}\text { Receiving chronic treatment with diuretics, either loop-diuretics, thiazide diuretics or } \\
\text { mineralocorticoid receptor antagonists }\end{array}$ \\
\hline $\begin{array}{l}\text { Angiotensin-converter enzyme (ACE) } \\
\text { inhibitors or angiotensin-II receptor blocker }\end{array}$ & Receiving chronic treatment with ACE inhibitors or angiotensin-II receptor blocker \\
\hline Beta-blocker & Receiving chronic treatment with beta-blocker \\
\hline Mineralocorticoid-receptor antagonists & Receiving chronic treatment with aldosterone-receptor antagonists \\
\hline Digoxin & Receiving chronic treatment with digoxin \\
\hline \multicolumn{2}{|c|}{ VITAL SIGNS AT EMERGENCY DEPARTMENT ARRIVAL } \\
\hline Systolic blood pressure & $\begin{array}{l}\text { Systolic blood pressure (SBP) measured in } \mathrm{mmHg} \text { of the patient on arrival to the ED. This value } \\
\text { can be that obtained during triage or the first taken on initiating care. }\end{array}$ \\
\hline Heart rate & $\begin{array}{l}\text { Central heart rate measured as beats per minute of the patient on arrival to the ED. V This } \\
\text { value can be that obtained during triage or the first taken on initiating care . }\end{array}$ \\
\hline Arterial oxygen saturation & $\begin{array}{l}\text { Oxygen saturation expressed as percentage obtained by capillary pulsioxymetry on arrival to } \\
\text { the ED. This value can be that obtained during triage or the first taken on initiating care. }\end{array}$ \\
\hline \multicolumn{2}{|c|}{ BLOOD TESTS AT EMERGENCY DEPARTMENT ARRIVAL } \\
\hline Glucose & $\ln \mathrm{mg} / \mathrm{dL}$ \\
\hline Creatinine & $\ln \mathrm{mg} / \mathrm{dL}$ \\
\hline Haemoglobin & $\ln \mathrm{g} / \mathrm{dL}$ \\
\hline Leukocytes & In cell/ $\mu \mathrm{L}$ \\
\hline Potassium & In $\mathrm{mmol} / \mathrm{L}$ \\
\hline Sodium & In $\mathrm{mmol} / \mathrm{L}$ \\
\hline Raised troponin & Indicate if troponin is above the 99th percent provided by the manufacturer \\
\hline
\end{tabular}




\begin{tabular}{|c|c|}
\hline NT-proBNP & In $\mathrm{pg} / \mathrm{mL}$ \\
\hline \multicolumn{2}{|c|}{ TRIGGERING FACTORS OF THE CURRENT EPISODE OF ACUTE HEART FAILURE } \\
\hline Infection & Active infection, of any system, considered to have a role in acute decompensation \\
\hline Rapid atrial fibrillation & Mean heart rate $>100 \mathrm{bpm}$, considered to have a role in acute decompensation \\
\hline Anaemia & Haemoglobin $<80 \mathrm{~g} / \mathrm{L}$, considered to have a role in acute decompensation \\
\hline Hypertensive emergency & Systolic blood pressure $>180 \mathrm{mmHg}$, considered to have a role in acute decompensation \\
\hline Acute coronary syndrome & Symptoms starting before decompensation, and not developing after dyspnoea appearance \\
\hline Dietetic/Therapeutic transgression & High water or sodium intake, omission to take drugs prescribed for heart failure treatment \\
\hline Other & $\begin{array}{l}\text { Describe specifically other adjudicated causes of decompensation not included in the previous } \\
\text { episodes }\end{array}$ \\
\hline Multifactorial & $\begin{array}{l}\text { When some factors concur, but none is of sufficient magnitude to explain the } \\
\text { decompensation by itself }\end{array}$ \\
\hline None identified & When none of the previous factors can be selected \\
\hline
\end{tabular}

